\title{
EFFECT OF Ni ATOMIC PERCENT ON Ni DISPERSION AND CATALYTIC ACTIVITY IN PREPARATION OF CATALYSTS FROM La-NI INTERMETALLIC COMPOUNDS
}

\author{
TADASHI SHIROTSUKA, KAORU ONOE AND AYUMU YOKOYAMA \\ Department of Applied Chemistry, Waseda University, Tokyo 160
}

Key Words: Chemical Reaction, Rare Earth Compound, Intermetallic Catalyst, Hydrogenation, Oxidation, Carbon Monoxide, Dispersion, Turnover Frequency, Conductivity

\begin{abstract}
A previous study showed that oxidation of $\mathrm{LaNi}_{5}$ could produce catalysts with a relatively high $\mathrm{Ni}$ dispersion. This study focuses on the effect of Ni atomic percent $\alpha$ upon Ni dispersion $\delta$ and turnover frequency $T F$, using $\mathrm{La}-\mathrm{Ni}$ compounds. It was found that the value of $\delta$ was higher in the order of $\mathrm{LaNi}_{5}>\mathrm{La}_{2} \mathrm{Ni}_{7}>\mathrm{LaNi}_{3}>\mathrm{LaNi}$ and that this order was related to oxidation rate. The value of $T F$, on the other hand, was higher in the reverse order, indicating that high oxidation rate causes severe defects on the surface of Ni crystallites.
\end{abstract}

\section{Introduction}

Recently, much attention has been paid to a new method of preparing catalysts by oxidation treatment of rare earth intermetallic compounds, because this method prevents the poisoning effect of residual ions or impurities upon catalytic activity and selectivity, which occurs with the conventional method using aqueous solutions. ${ }^{5,6)}$

Additionally, in this intermetallic compound method, catalysts containing highly dispersed transition metals, such as $\mathrm{Ni}$ and $\mathrm{Co}$, can be obtained by regulating several influencing factors, such as oxidation temperature, oxidation time and reduction temperature. For example, it was shown that in the case of $\mathrm{LaNi}_{5}$, only $\mathrm{La}$ can be oxidized selectively in the low-temperature region (approximately $623 \mathrm{~K}$ ), and that well-dispersed $\mathrm{Ni}$ on $\mathrm{La}_{2} \mathrm{O}_{3}$ can be obtained. ${ }^{5)}$

This study concerns the effect of $\mathrm{Ni}$ atomic percent $\alpha[\%]$ upon oxidation rate, $\mathrm{Ni}$ dispersion $\delta$ and turnover frequency $T F$ of the synthesis gas reaction, using $\mathrm{LaNi}, \mathrm{LaNi}_{3}, \mathrm{La}_{2} \mathrm{Ni}_{7}$ and $\mathrm{LaNi}_{5}$. It was found that only La could be oxidized in the low-temperature region, producing $\mathrm{Ni} / \mathrm{La}_{2} \mathrm{O}_{3}$ catalysts with all four compounds.

\section{Experimental}

\subsection{Materials}

According to the phase diagram of La-Ni made by Buschow et al., ${ }^{1)}$ intermetallic compounds are formed when $\mathrm{Ni} / \mathrm{La}$ atomic ratios are 1.0, 3.0, 3.5 and 5.0,

Received December 7, 1985. Correspondence concerning this article should be addressed to $\mathrm{K}$. Onoe. and they are stable up to about $1000 \mathrm{~K}$ at atmospheric pressure.

The crystal structures are known: LaNi is orthorhombic; $\mathrm{LaNi}_{3}$ is rhombohedral; $\mathrm{La}_{2} \mathrm{Ni}_{7}$ and $\mathrm{LaNi}_{5}$ are hexagonal.

To make these compounds, $99.7 \mathrm{wt} \%$ purity of La (impurities are $0.18 \mathrm{wt} \% \mathrm{Nd}, 0.05 \mathrm{wt} \% \mathrm{Pr}, 0.05 \mathrm{wt} \%$ $\mathrm{Ce}, 0.02 \mathrm{wt} \% \mathrm{Fe}$ ) and $99.97 \mathrm{wt} \%$ purity of $\mathrm{Ni}$ (impurities are $0.005 \mathrm{wt} \% \mathrm{Fe}, 0.005 \mathrm{wt} \% \mathrm{Cu}, 0.01 \mathrm{wt} \% \mathrm{~Pb}$, the rest are $\mathrm{Mn}, \mathrm{C}, \mathrm{S}$ ) were mixed in appropriate ratios in a copper boat. The mixture was repeatedly induction-melted in an argon atmosphere to obtain a homogeneous melt, and was then water-cooled to form sample crystals.

$\mathrm{X}$-ray diffraction patterns of these samples showed that $\mathrm{LaNi}, \mathrm{LaNi}_{3}, \mathrm{La}_{2} \mathrm{Ni}_{7}$ and $\mathrm{LaNi}_{5}$ were formed.

1.2 Effects of impurities and grain boundaries on oxidation rates

It has been reported that oxidation rate is greatly influenced by impurities and grain boundaries in crystais. ${ }^{7)}$ The impurities and grain boundaries in these La-Ni compounds have the same effects upon both conductivity before oxidation and oxidation rate.

To study the effects of these factors upon oxidation rate, the conductivity $\sigma$ of La-Ni compounds was measured, and the relation between $\sigma$ and the number $x$ of $\mathrm{Ni}$ atoms per unit of $\mathrm{LaNi}_{x}$ was examined as a tool for predicting the effect of impurities and grain boundaries upon the oxidation rate. Thus, if $\sigma$ were found be correlated with $x$ by Kirkpatrick's equation Eq. (1), the effect of impurities and grain boundaries upon the oxidation rate would be negligible or the 
same for all four La-Ni compounds.

$$
\sigma=A x^{B}
$$

The apparatus for measuring conductivity is shown in Fig. 1. After the current was measured from the voltage drop across the standard resistance (1) $(1.000 \Omega)$, samples $(100 / 170$ mesh) were placed in glass tube (2) (5 $\mathrm{mm}$ diameter) and then pressed by weight (3) to pack them homogeneously. Conductivity was measured at $293 \mathrm{~K}$ with samples of the appropriate length at the appropriate pressure. It was determined that neither factor has any influence on conductivity. ${ }^{2)}$

\subsection{Measurement of oxidation rate}

Oxidation rate was measured using the thermogravimeter (Shimadzu TG-30). ${ }^{5}$ A $100 \mathrm{mg}$ sample $(100 / 170$ mesh) was placed on the cell, and the weight change was measured at $600-623 \mathrm{~K}$ in $\mathrm{O}_{2} / \mathrm{He}$ gas at a flow rate sufficient to eliminate gas-film resistance.

\subsection{Measurement of structural change and Ni crystal-} lite size

The X-ray diffraction method was used to study changes in structure and to measure Ni crystallite size at the $\mathrm{Ni}(111)$ peak.

\subsection{Measurement of catalytic activity}

After samples were oxidized in the reactor of the thermogravimeter, the oxygen was replaced by helium, and samples were reduced at $723 \mathrm{~K}$ by hydrogen. Hydrogen was then purged by helium, and the initial activity was measured in $\mathrm{H}_{2} / \mathrm{CO}$ gas $\left(\mathrm{H}_{2} / \mathrm{CO}=3\right)$ at $673-723 \mathrm{~K}$, using FID and TCD gas chromatography.

The oxidation, reduction and reaction were all conducted in the thermogravimeter.

\section{Results and Discussion}

\subsection{Effects on oxidation rate of lattice spattering}

According to Wagner's oxidation theory, ${ }^{4}$ lattice spattering caused by impurities and grain boundaries changes the concentration of vacant sites and thus alters the diffusion rate in the oxide layers. As $\alpha$ changes,

1) lattices might be spattered differently by impurities such as other rare earth metals in the $\mathrm{La}$, or $\mathrm{Cu}$ or $\mathrm{Fe}$ in the $\mathrm{Ni}$; and

2) the properties of the grain boundaries might change, and lattices might be spattered differently.

Therefore, the conductivity of La-Ni intermetallic compounds was measured to study the effects of impurities and grain boundaries. The influence of $x$ on conductivity $\sigma\left[\Omega^{-1} \cdot \mathrm{m}^{-1}\right]$ show good linearity on a $\log -\log$ graph, Fig. 2, and the relation agrees with Kirkpatrick's equation Eq. (1), where:

$$
\begin{aligned}
& \mathrm{A}=501 \Omega^{-1} \cdot \mathrm{m}^{-1} \\
& \mathrm{~B}=2.5,
\end{aligned}
$$
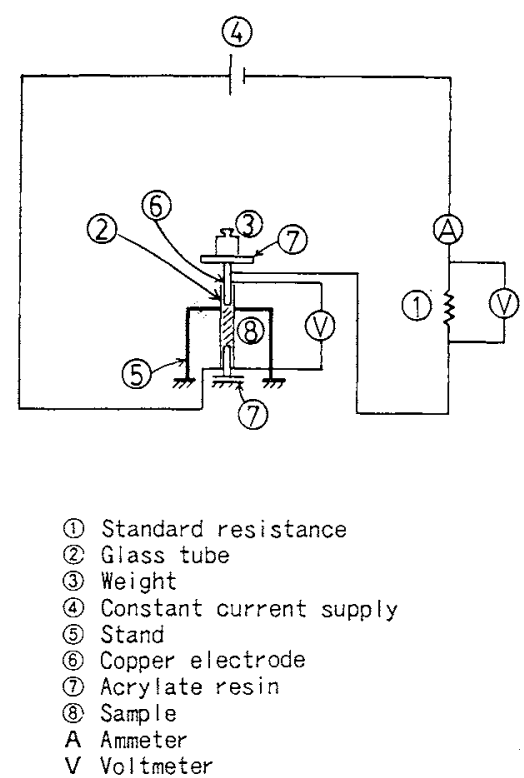

Fig. 1. Apparatus for measuring conductivity.

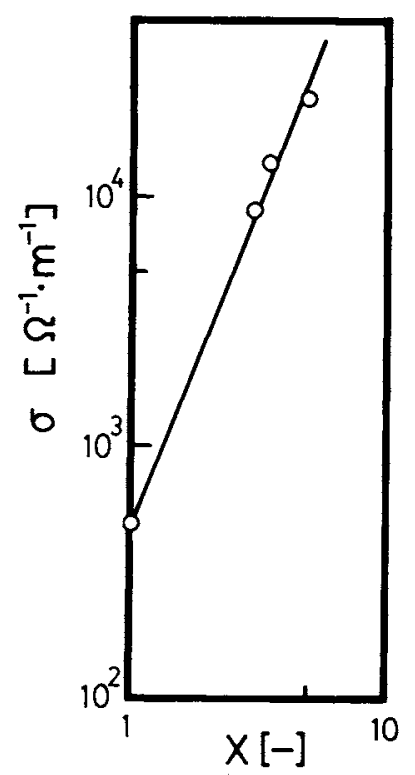

Fig. 2. Influence of number of $\mathrm{Ni}$ atoms per unit of $\mathrm{LaNi}_{x}$ on conductivity.

indicating that the diffusion rate in the oxide layers is not influenced by the impurities or grain boundaries in any of the La-Ni compounds studied. ${ }^{7)}$

\subsection{Effect of $\alpha$ on La oxidation rate}

The weight increase stopped at the weight change calculated for complete oxidation of $\mathrm{La}$, as shown in Fig.3. To confirm the nature of the substances formed during oxidation, powder X-ray diffraction studies were made. For the oxidized La-Ni compounds at the points corresponding to the weight increase for the complete conversion of $\mathrm{La}$ into $\mathrm{La}_{2} \mathrm{O}_{3}$, the diffraction patterns showed only the existence of $\mathrm{La}_{2} \mathrm{O}_{3}$ and metallic Ni.

This showed that for $\mathrm{LaNi}, \mathrm{LaNi}_{3}$ and $\mathrm{La}_{2} \mathrm{Ni}_{7}$, only La was oxidized at $623 \mathrm{~K}$, and agrees with results 


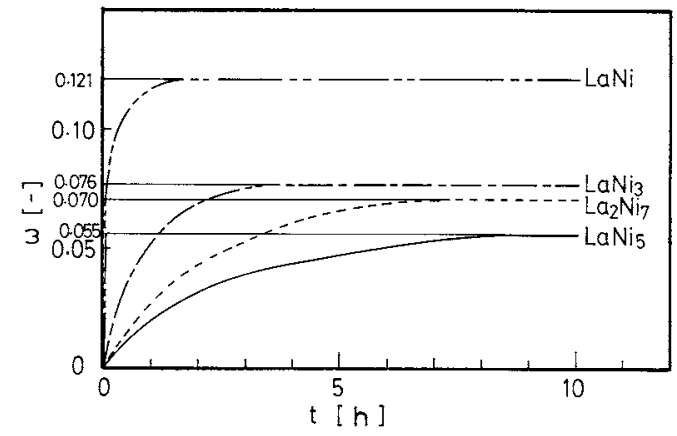

Fig. 3. Time course of weight change during oxidation of $\mathrm{LaNi}, \mathrm{LaNi}_{3}, \mathrm{La}_{2} \mathrm{Ni}_{7}$ and $\mathrm{LaNi}_{5}$ at $623 \mathrm{~K}$.

previously obtained for $\mathrm{LaNi}_{5} .{ }^{5}$ Additionally, no powdering during oxidation was observed with the optical microscope.

At oxidation temperatures lower than $603 \mathrm{~K}$, La was not completely oxidized after 15 hours, and the catalytic activity changed owing to the transformation of unoxidized La in synthesis gas atmosphere. Therefore, all subsequent oxidation was conducted at $623 \mathrm{~K}$.

Using emery-ground samples, the movement of a distinct interface between oxidized parts and intermetallic compounds into the center of particles was observed, showing that La oxidation in the four La$\mathrm{Ni}$ compounds follows the core model. It was found from the relation between oxidation time and conversion that diffusion in the oxide layer is the ratedetermining step.

Based on the core model, the fraction of La oxidized $X_{s}[-]$ is related to an oxidation parameter $\beta\left[\mathrm{s}^{-1}\right]$ in Eq. (2), where $\beta$ is expressed by Eq. (3).

$$
\begin{aligned}
& \beta=1 / t\left\{1 / 2-\left(1-X_{s}\right)^{2 / 3} / 2-X_{s} / 3\right\} \\
& \beta=v C_{g} D /\left(\rho \cdot R^{2}\right)
\end{aligned}
$$

Figure 4 shows that the diffusion rate slows as $\alpha$ increases. In $\mathrm{La}$ oxidation, oxygen diffuses in the $\mathrm{La}_{2} \mathrm{O}_{3}$ crystal lattices; ${ }^{3)}$ therefore, it was assumed that the number of vacant sites decreases with increasing $\alpha$ because some of the $\mathrm{La}$ (III) cation points in the lattice are replaced by $\mathrm{Ni}$ (II) cations. The decrease of vacant sites seemed to slow the diffusion rate.

The high degree of linearity of the relationship in Fig. 4 indicates that the oxidation rate depends upon $\alpha$ but not on the crystal structure.

\subsection{Effect of $\alpha$ on $\mathrm{Ni}$ dispersion}

After the La of the four compounds was completely oxidized at $623 \mathrm{~K}$, Ni dispersion was measured. Figure 5 shows that $\mathrm{Ni}$ dispersion is higher in the order of $\mathrm{LaNi}_{5}>\mathrm{La}_{2} \mathrm{Ni}_{7}>\mathrm{LaNi}_{3}>\mathrm{LaNi}$, i.e., Ni dispersion is higher with increases in $\alpha$. Figures 4 and 5 show that $\delta$ decreases with increasing $\beta$.

As a result, it is concluded that the oxidation rate determines $\delta$ for different values of $\alpha$. The same effect

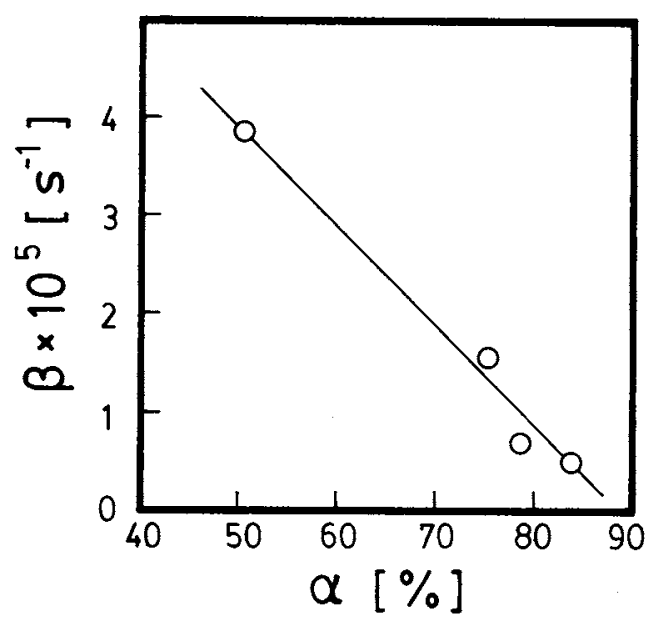

Fig. 4. Relation between Ni atomic percent and oxidation rate parameter.

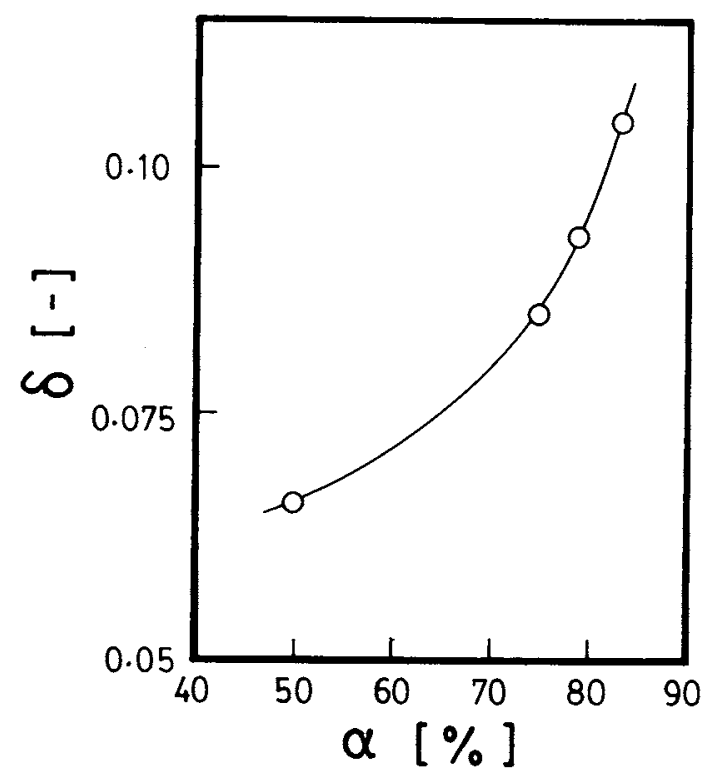

Fig. 5. Relation between $\mathrm{Ni}$ atomic percent and $\mathrm{Ni}$ dispersion.

was found in the case of different values of $T$.

It is to be noted that $\delta$ is controlled either by $\alpha$, the structure factor, or/and by experimental factors such as the oxidation temperature or the oxygen partial pressure.

\subsection{Effect of $\alpha$ on turnover frequency}

The initial activity of catalysts prepared by the complete oxidation of $\mathrm{La}$ in the four compounds was measured, and Fig. 6 shows that the initial rate of $\mathrm{CO}$ conversion per gram of $\mathrm{Ni}, r_{0}\left[\mathrm{mmol} \cdot \mathrm{kg}^{-1} \cdot \mathrm{s}^{-1}\right]$, increased with decreasing $\alpha$. Over $99 \%$ of the product was methane.

Next, turnover frequency $T F\left[\mathrm{~s}^{-1}\right]$ was calculated. The number of active sites necessary for the calculation of $T F$ was assumed to be the same as the number of $\mathrm{Ni}$ atoms on the surface, which was determined using the value of $\mathrm{Ni}$ dispersion and the total number of $\mathrm{Ni}$ atoms. Figure 7 shows that $T F$ 


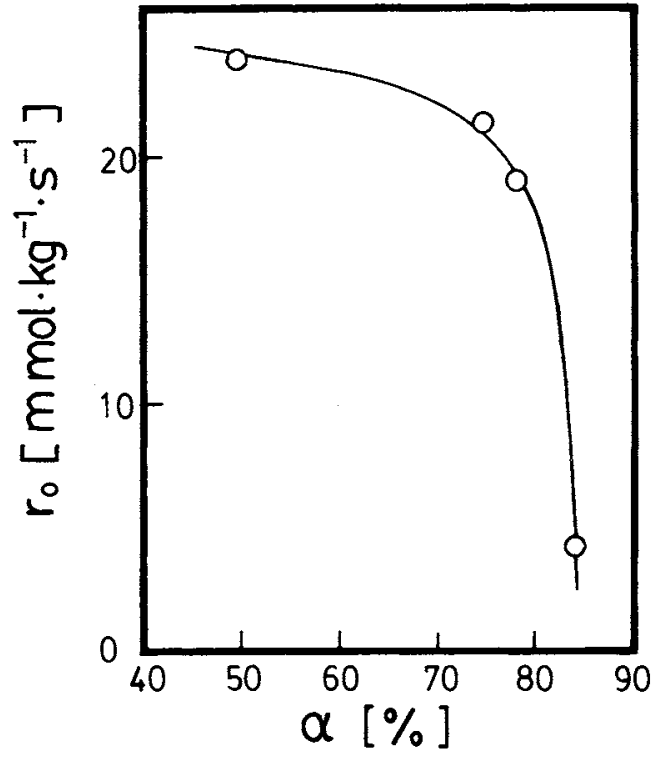

Fig. 6. Relation between $\mathrm{Ni}$ atomic percent and initial activity for $\mathrm{CO}$ hydrogenation at $673 \mathrm{~K}$.

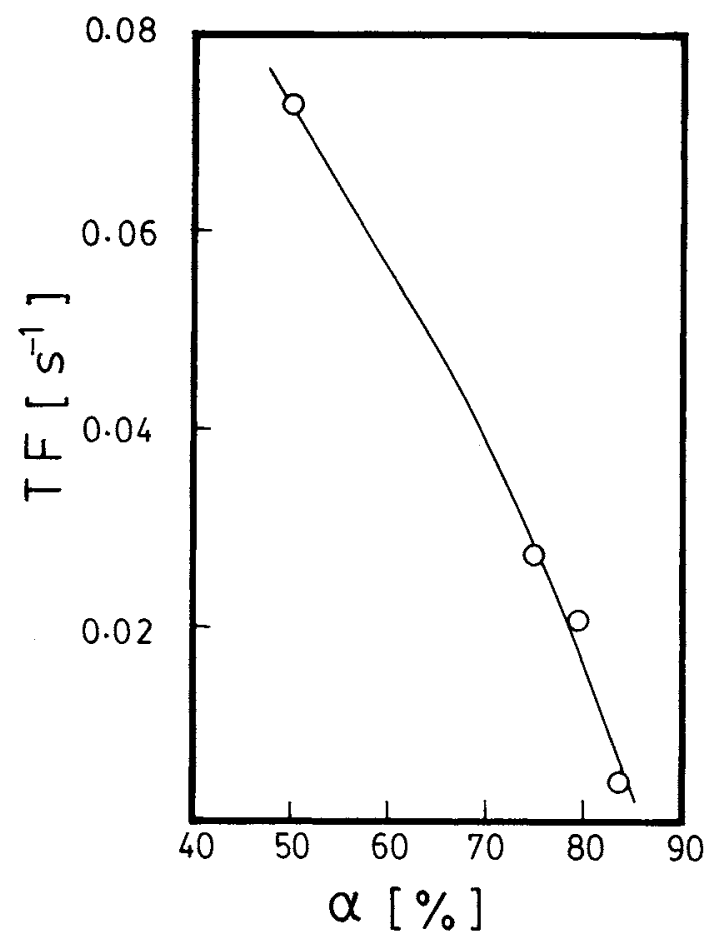

Fig. 7. Relation between $\mathrm{Ni}$ atomic percent and turnover frequency at $673 \mathrm{~K}$.

increases as $\alpha$ decreases. As noted in Section $\mathbf{2 . 5}$ below, the activation energy was the same for the four catalysts, so that the effective $T F$ should be the same. The change in $T F$ is believed to be due to the fact that the degree of defects varies with the oxidation rate which, in turn, varies with $\alpha$. This supposition was supported by the fact that a steady rate of $\mathrm{CO}$ conversion was obtained earlier as $\alpha$ decreased.

\subsection{Effect of $\alpha$ on activation energy}

Arrhenius' plots of the four samples of catalysts

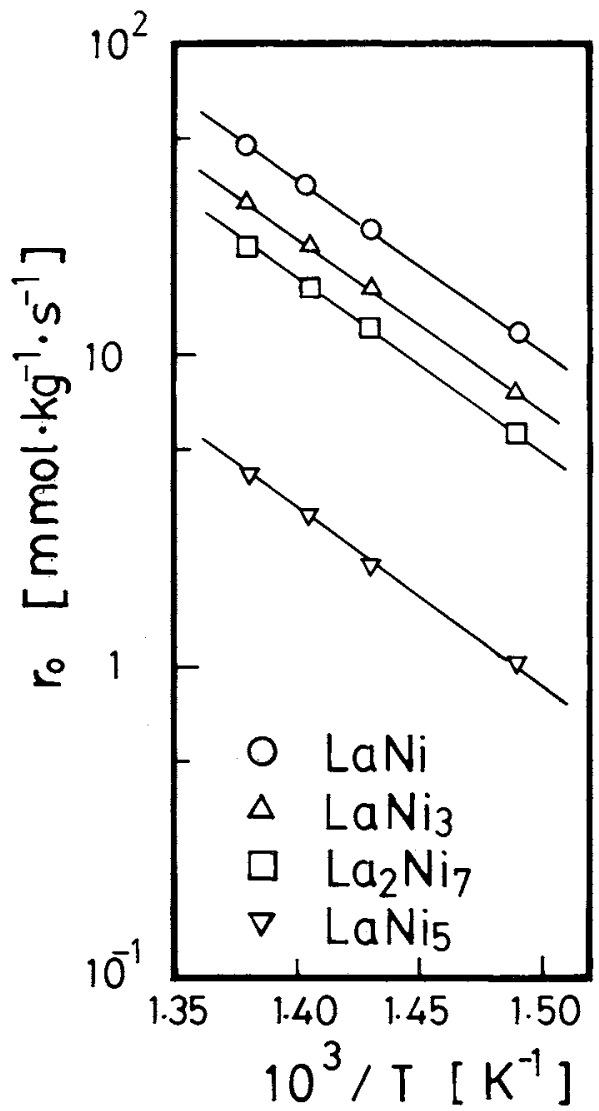

Fig. 8. Dependence of initial activity on temperature for $\mathrm{CO}$ hydrogenation over the four catalysts produced from LaNi compounds.

Table 1. Activation energy for $\mathrm{CO}$ hydrogenation

\begin{tabular}{cc}
\hline & $\Delta E\left[\mathrm{~kJ} \cdot \mathrm{mol}^{-1}\right]$ \\
\hline $\mathrm{LaNi}$ & 100 \\
$\mathrm{LaNi}_{3}$ & 107 \\
$\mathrm{La}_{2} \mathrm{Ni}_{7}$ & 103 \\
$\mathrm{LaNi}_{5}$ & 110 \\
\hline$T=673-723 \mathrm{~K}, \mathrm{H}_{2} / \mathrm{CO}=3, F_{\mathrm{Co}} / W=152.5 \mathrm{mmol} \cdot \mathrm{kg}^{-1} \cdot \mathrm{s}^{-1}$ \\
\hline
\end{tabular}

prepared by complete oxidation of $\mathrm{La}$ are shown in Fig. 8. The reaction was conducted using synthesis gas at $673-723 \mathrm{~K}$. To study the sintering of Ni crystallites, the four catalysts obtained after the complete oxidation of La were kept in helium at $723 \mathrm{~K}$ for 5 hours. The Ni crystallites were found to be of the same size, indicating that sintering did not occur. Figure 8 and Table 1 show that the apparent activation energy $\Delta E$ $\left[\mathrm{kJ} \cdot \mathrm{mol}^{-1}\right]$ does not depend upon $\alpha$, and was approximately the same as for one of the conventional supported $\mathrm{Ni}$ catalysts $^{8)}$ that have small $\mathrm{Ni}$ content $(\sim 1 \mathrm{wt} \%)$ and large pore volume.

\section{Conclusion}

1) For $\mathrm{LaNi}, \mathrm{LaNi}_{3}, \mathrm{La}_{2} \mathrm{Ni}_{7}$ and $\mathrm{LaNi}_{5}$, only $\mathrm{La}$ was oxidized at temperatures lower than $623 \mathrm{~K}$, and the oxidation mechanism followed the core model. 
2) $\mathrm{Ni}$ dispersion in samples after complete oxidation of $\mathrm{La}$ at $623 \mathrm{~K}$ was greater in the order $\mathrm{LaNi}_{5}>\mathrm{La}_{2} \mathrm{Ni}_{7}>\mathrm{LaNi}_{3}>\mathrm{LaNi}$. This order was found to result from differences in the oxidation rates.

3) Turnover frequency calculated from the synthesis gas reaction was greater in the order $\mathrm{LaNi}>\mathrm{LaNi}_{3}>\mathrm{La}_{2} \mathrm{Ni}_{7}>\mathrm{LaNi}_{5}$, and this can be attributed to the difference in the degree of defects, which varies with oxidation rate.

\begin{tabular}{|c|c|c|}
\hline \multicolumn{3}{|c|}{ Nomenclature } \\
\hline $\mathrm{C}_{g}$ & $=$ oxygen concentration in bulk phase & \\
\hline & & {$\left[\mathrm{mol} \cdot \mathrm{m}^{-3}\right]$} \\
\hline$D$ & $=$ diffusion coefficient & {$\left[\mathrm{m}^{2} \cdot \mathrm{s}^{-1}\right]$} \\
\hline$\Delta E$ & $=$ activation energy & {$\left[\mathrm{kJ} \cdot \mathrm{mol}^{-\mathrm{t}}\right]$} \\
\hline$R$ & $=$ radius of solid particle & {$[\mathrm{m}]$} \\
\hline$r_{0}$ & $\begin{array}{r}=\text { initial rate of } \mathrm{CO} \text { conversion per gram } \\
{[[\mathrm{mmol}]}\end{array}$ & $\begin{array}{l}\text { of } \mathrm{Ni} \\
\left.\cdot \mathrm{kg}^{-1} \cdot \mathrm{s}^{-1}\right]\end{array}$ \\
\hline$t$ & $=$ time & {$[\mathrm{h}],[\mathrm{s}]$} \\
\hline$T$ & $=$ temperature & {$[\mathrm{K}]$} \\
\hline$T F$ & $=$ turnover frequency & {$\left[s^{-1}\right]$} \\
\hline$x$ & $=$ number of $\mathrm{Ni}$ atoms per unit of $\mathrm{LaNi}_{x}$ & {$[-]$} \\
\hline$X_{s}$ & $=$ conversion of $\mathrm{La}$ to $\mathrm{La}_{2} \mathrm{O}_{3}$ & {$[-]$} \\
\hline
\end{tabular}

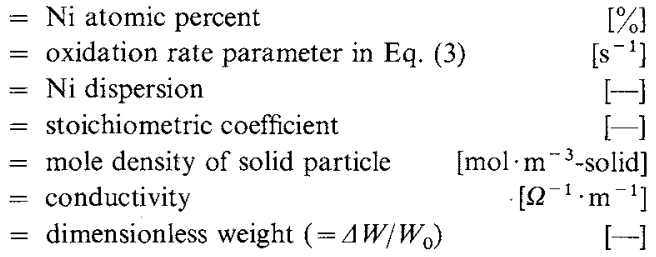

\section{Literature Cited}

1) Buschow, K. H. J. and H. H. Van Mal: J. Less-Common Metals, 29, 203 (1972).

2) Hunter, L. P.: "Handbook of Semiconductor Electronics," p. 202, 2nd ed., McGraw-Hill (1962).

3) Katou, T. and H. Yanagida: "Rare-earth," p. 262, GihouDou (1980).

4) Kubaschewski, O. and B. E. Hopkins: "Oxidation of Metals and Alloys," p. 26, Butterworths Scientific Publications (1953).

5) Shirotsuka, T., K. Onoe and A. Yokoyama: J. Chem. Eng. Japan, 19, 91 (1986).

6) Shirotsuka, T., K. Onoe and A. Yokoyama: J. Chem. Eng. Japan, 19, 347 (1986)

7) Tsuda, N., A. Yanase and K. Shiratori: "Denki-DendouseiSankabutu," p. 241, Shouka-Bou (1983).

8) Vannice, M. A.: J. Catal., 37, 462 (1975).

\title{
KINETICS AND MECHANISM OF ZINC EXTRACTION FROM SULFATE MEDIUM WITH DI(2-ETHYLHEXYL) PHOSPHORIC ACID
}

\author{
TING-CHIA HUANG AND RUEY-SHIN JUANG \\ Department of Chemical Engineering, National Cheng Kung University, \\ Tainan, Taiwan 70101, R.O.C.
}

Key Words: Extraction, Stripping, Zinc, Di(2-ethylhexyl) Phosphoric Acid, Interfacial Reactions, Kinetics, Mechanism

\begin{abstract}
Kinetic studies of the extraction of zinc from aqueous sulfate solution by di(2-ethylhexyl) phosphoric acid in kerosene were made, using a constant interfacial area cell. Measurements of the extraction and stripping rates led to the identification of rate expressions and a suggested mechanism of this reaction. Based on the nature of the extractant and the reaction mechanism for the formation of zinc complex in the aqueous phase, a simple extraction scheme is proposed in which the rate-controlling step is interfacial. The mass-action constant obtained in the present kinetic study is considered to agree with the extraction constant obtained in the previous equilibrium study. Effects of the total sulfate concentration in the aqueous phase on the extraction and stripping rates were also investigated.
\end{abstract}

\section{Introduction}

The kinetics of metal extraction by chelating agents is essential in solvent extraction and liquid membrane

\footnotetext{
Received December 13, 1985. Correspondence concerning this article should be addressed to $T$. C. Huang.
}

operations. In most cases the extraction rate of metal ions is a function of both the kinetics of chemical reactions taking place in the system and the rates of diffusion of the species between the two phases. The simultaneous presence of both chemical reactions and diffusion processes in liquid-liquid mass transfer has 